\title{
A nanoindentation analysis of the effects of microstructure on elastic properties of $\mathrm{Al}_{2} \mathrm{O}_{3} / \mathrm{SiC}$ composites
}

\author{
Zhong Ling ${ }^{\mathrm{a}, *}$, Jinping Hou ${ }^{\mathrm{b}}$ \\ ${ }^{\text {a }}$ LNM, Institute of Mechanics, Chinese Academy of Sciences, Beijing 100080, China \\ ${ }^{\mathrm{b}}$ Department of Engineering Mechanics, Zhengzhou University, 75 Daxue Road, Zhengzhou 450052, China
}

Received 3 November 2005; received in revised form 13 February 2007; accepted 26 April 2007

Available online 13 May 2007

\begin{abstract}
Nanoindentation tests were carried out to investigate certain elastic properties of $\mathrm{Al}_{2} \mathrm{O}_{3} / \mathrm{SiC}_{p}$ composites at microscopic scales (nm up to $\mu \mathrm{m}$ ) and under ultra-low loads from $3 \mathrm{mN}$ to $250 \mathrm{mN}$, with special attention paid to effects caused by SiC particles and pores. The measured Young's modulus depends on the volume fraction of $\mathrm{SiC}$ particles and on the composite porosity and it can compare with that of alumina. The Young's modulus exhibits large scatters at small penetrations, but it tends to be constant with lesser dispersion as the indentation depth increases. Further analysis indicated that the scatter results from specific microstructural heterogeneities. The measured Young's moduli are in agreement with predictions, provided the actual role of the microstructure is taken into account.
\end{abstract}

(C) 2007 Elsevier Ltd. All rights reserved.

Keywords: A. Ceramic-matrix composites (CMCs); B. Microstructures; C. Elastic properties; Nanoindentation test

\section{Introduction}

The nanoindentation technique has been developed over the last few decades as an effective tool for probing mechanical properties of materials at very small scales $(\mathrm{nm}-\mu \mathrm{m})$. Its principal advantage is to continuously monitor with high precision and accuracy both the load $(P)$ and displacement $(h)$ of an indenter during loading and unloading in the micro-Newton and nanometer ranges [1-3]. Based on the analysis of the loadingunloading data derived from indentation tests, elastic moduli $(E)$ and hardnesses $(H)$ can be determined. Nanoindentation has been applied to a variety of solids including metals, ceramics, almost all homogenous and monolithic [1-7]. Taking advantage of the sensitivity of the indenter tip to microstructural features at the submicron-nanometer scale, nanoindentation investigations on heterogeneous materials or multiphase composites have

\footnotetext{
* Corresponding author.

E-mail addresses: lingz@LNM.imech.ac.cn (Z. Ling), jinpinghou@ zzu.edu.cn (J. Hou).
}

also been reported [8-13]. The indenter tip can accurately probe very small volumes, even in anisotropic materials or multiphase composites. For instances, Fan et al. [9] could quantitatively evaluate the local anisotropy of human bones. Ling [10] applied this technique to probing the elastic properties of different phases of a ceramic composite, with the tip indenting the different phases selectively. A limitation takes place though when heterogeneities scale with the size of the nanoindent. This was illustrated by $\mathrm{Hu}$ and Lawn [11] who studied the indentation stress-strain behaviour of bilayer composites, in which case the microstructure scales with the layer thickness. In the same vein, Jung et al. [12] evaluated the mechanical properties of composite bilayers by nanoindentation. In polycrystalline $\mathrm{Al}_{2} \mathrm{O}_{3}$, Gong et al. [13] remarked that when the maximum indentation depth compares with the grain size of the tested material, the mechanical properties probed by nanoindentation reflect local rather than bulk properties. In this context, it is essential to understand further how the nanoindentation can help probing the effects of heterogeneities on the mechanical properties of multiphase materials. 
In this work, alumina and multiphase ceramic composites, $\mathrm{Al}_{2} \mathrm{O}_{3} / \mathrm{SiC}$, were studied. In the composites, $\mathrm{SiC}$ particles are embedded within alumina grains engendering heterogeneous microstructures at the nm-scale and up to the $\mu \mathrm{m}$-scale, which makes the composite fully appropriate to pursue the above-mentioned goals. The microstructure heterogeneity is at the origin of the fracture mode transforming from predominantly intergranular in alumina to predominantly transgranular in the composite $[14,15]$.

\section{Experimental procedure}

\subsection{Materials and test conditions}

Alumina and its composites, $\alpha-\mathrm{Al}_{2} \mathrm{O}_{3} / \mathrm{SiC}$ with 5 and $10 \%$ volume fraction of $\mathrm{SiC}$ particles used in this study were provided by the Institute of Ceramics, Chinese Academy of Sciences. A solid alumina sample was fabricated from as-received powders by sintering at $1550{ }^{\circ} \mathrm{C}$ for 30 min under $30 \mathrm{MPa}$. For the composites, the $\mathrm{SiC}$ powder with a mean particle size of about $60-100 \mathrm{~nm}$, was first dispersed and then mixed with $\mathrm{Al}_{2} \mathrm{O}_{3}$ powder. The mixture was dried, sieved, calcined, and then sintered at $1700^{\circ} \mathrm{C}$ for $30 \mathrm{~min}$ at $30 \mathrm{MPa}$. The density was determined from separate measurement of the mass and volume of each disc. For each sample, the morphology of the microstructure was characterized on freshly fractured surfaces in a highresolution scanning electron microscope (SEM Sirion400NC).

Fig. 1 presents the fracture surfaces of both alumina and its composite containing $5 \mathrm{vol} . \% \mathrm{SiC}$ particles. The size of the alumina grains is about $2 \mu \mathrm{m}$ in the single-phase alumina samples (Fig. 1a) and about $5 \mu \mathrm{m}$ in the composite (Fig. 1b). Both grain sizes being larger than the depths of nanoindentation, it is reasonable to assume that the elastic properties probed away from grain boundaries and $\mathrm{SiC}$ particles should scale with those of single crystal alumina (sapphire). The mean size of $\mathrm{SiC}$ particles in the composites is about $100 \mathrm{~nm}$, close to the starting sizes of the powders.
It can also be noticed from Fig. 1 that the fracture mode is almost intergranular for alumina (Fig. 1a) and dominantly transgranular for the composite, a difference which can therefore be ascribed to the $\mathrm{SiC}$ particles (Fig. 1b). The specimen size was $15 \times 3 \times 3 \mathrm{~mm}$ with flat-machined parallel surfaces. Each test surface was finely diamond-polished to scratch-free mirror-like, suitable for indentation tests.

The mean distance between two nearest-neighbouring particles, $\delta_{\mathrm{SiC}}$, can be expressed as [16]

$\delta_{\mathrm{SiC}}=\frac{d_{\mathrm{s}}}{2}\left(\sqrt{\frac{2 \pi}{3 f_{\mathrm{v}}}}-\sqrt{\frac{8}{3}}\right)$

where, $d_{\mathrm{s}}$ is the particle size and $f_{\mathrm{v}}$ is the volume fraction of the particles. $\delta_{\mathrm{SiC}}$ is about $240 \mathrm{~nm}$ for $\mathrm{Al}_{2} \mathrm{O}_{3} / \mathrm{SiC}_{\mathrm{p}}(5 \%)$ and $150 \mathrm{~nm}$ for $\mathrm{Al}_{2} \mathrm{O}_{3} / \mathrm{SiC}_{\mathrm{p}}(10 \%)$. SiC particles distributed along the alumina grain boundaries are not taken into account. Before nanoindentation, the surface roughness, $R_{\mathrm{a}}$, amounted to 8.4, 15.9 and $9.4 \mathrm{~nm}$ for $\mathrm{Al}_{2} \mathrm{O}_{3}, \mathrm{Al}_{2} \mathrm{O}_{3} /$ $\mathrm{SiC}_{\mathrm{p}}(5 \%)$ and $\mathrm{Al}_{2} \mathrm{O}_{3} / \mathrm{SiC}_{\mathrm{p}}(10 \%)$, respectively. Except for shallow indentation depth, surface roughness is, however, not thought to have influenced the present results since most of the various length scales characterizing the microstructure together with the depth of nanoindentation were large enough compared to the roughness of each sample. Table 1 gives the main properties and the typical length scales of the tested materials. The reference Young's moduli of alumina $\mathrm{Al}_{2} \mathrm{O}_{3}$ and $\mathrm{SiC}$ were taken from the NIST database [17]. The densities of both tested composites are lower than that of alumina (Table 1), revealing the presence of pores.

The tests were performed at room temperature using a nanoindentation device (CSEM Instrument) equipped with a Berkovich tip. The device was fully calibrated with the Oliver-Pharr (O-P) method [2]. Considering the heterogeneity of the tested materials, smaller increments were used at lower load levels. The peak load levels were preset at 3 , $5,10,15,20,25,30 \mathrm{mN}$ and then from 50 to $250 \mathrm{mN}$ with an increment of $50 \mathrm{mN}$. The maximum peak load was less than the fracture threshold of alumina $[8,18]$. In each test, a

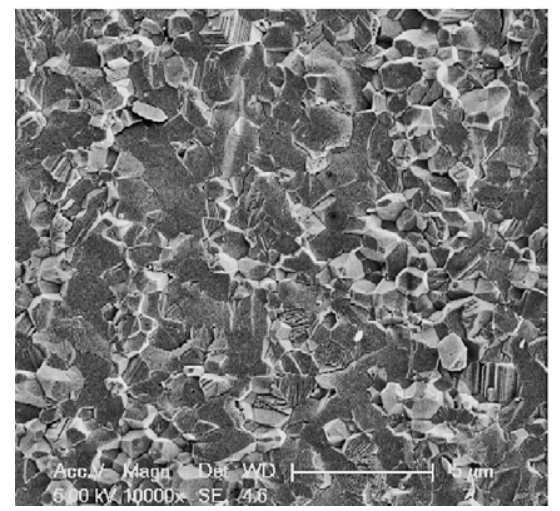

b

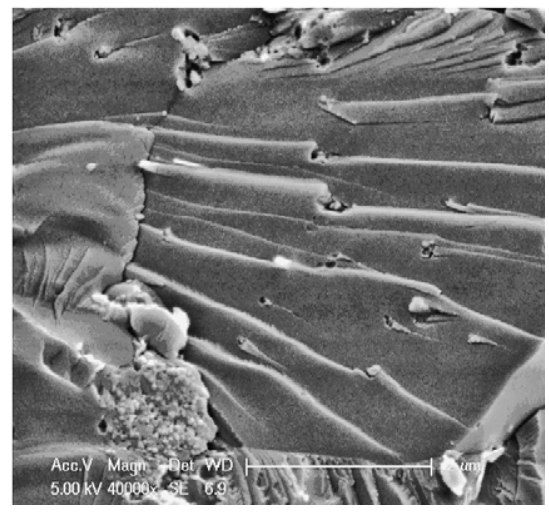

Fig. 1. Micrographs of the tested materials: (a) intergranular fracture in the pure alumina and (b) transgranular fracture in composite matrix grains, $\alpha-\mathrm{Al}_{2} \mathrm{O}_{3} / \mathrm{SiC}(5 \%)$, where small white $\mathrm{SiC}$ particles dispersed in the alumina grains. 
Table 1

Essential properties and coefficients of the tested materials

\begin{tabular}{|c|c|c|c|c|c|c|c|}
\hline Material & $E[17](\mathrm{GPa})$ & Density $\left(\mathrm{g} / \mathrm{cm}^{3}\right)$ & Density $\left(\mathrm{g} / \mathrm{cm}^{3}\right)$ & $d_{\mathrm{g}}(\mathrm{nm})$ & $\delta_{\mathrm{SiC}}(\mathrm{nm})$ & Porosity $(\%)$ & $R_{\mathrm{a}}(\mathrm{nm})$ \\
\hline$\alpha-\mathrm{Al}_{2} \mathrm{O}_{3}$ & $416 \pm 30$ & $3.984[17]$ & 3.98 & 2000 & - & 0.10 & 8.4 \\
\hline $\mathrm{SiC}$ particle & $430-460$ & 3.19 [17] & & $60-100$ & - & & \\
\hline$\alpha-\mathrm{Al}_{2} \mathrm{O}_{3} / \mathrm{SiC}_{\mathrm{p}}(5 \%)$ & & & 3.89 & 5000 & $145-242$ & 1.39 & 15.9 \\
\hline$\alpha-\mathrm{Al}_{2} \mathrm{O}_{3} / \mathrm{SiC}_{\mathrm{p}}(10 \%)$ & & & 3.84 & 5000 & $88-147$ & 1.68 & 9.4. \\
\hline
\end{tabular}

the indenter was driven into the specimen till the load reached the preset peak load level and then unloaded gradually to zero. The loading rate was $2 / \mathrm{min}([\Delta P / P] / \mathrm{min})$ for all the tests. Five tests were conducted at different locations for each value of the peak load.

\subsection{Methods of analysis}

Penetration was represented by the applied load, $P$, as a function of the indent depth, $h$. Several important local properties can be derived from the following equations $[1,2]$ :

$P=P(h), \quad S=\left.\frac{\mathrm{d} P}{\mathrm{~d} h}\right|_{h=h_{m}}=\frac{2}{\sqrt{\pi}} E_{\mathrm{r}} \sqrt{A\left(h_{\mathrm{c}}\right)}$

$\frac{1}{E_{\mathrm{r}}}=\frac{1-v^{2}}{E}+\frac{1-v_{i}^{2}}{E_{i}}$

where $S$, known as the contact stiffness, is the slope of the unloading curve at the maximum depth; $E_{\mathrm{r}}$ is the reduced modulus; $E$ and $v$ are the Young's modulus and Poisson's ratio of the tested material, respectively, and $E_{i}$ and $v_{i}$ are those for the indenter tip; $A\left(h_{\mathrm{c}}\right)$ is the projected area, itself a function of the contact surface obtained by the standard calibration procedure

$A=24.56 h_{\mathrm{c}}^{2}+C_{1} h_{\mathrm{c}}^{1}+C_{2} h_{\mathrm{c}}^{1 / 2}+C_{3} h_{\mathrm{c}}^{1 / 4}+\cdots+C_{8} h_{\mathrm{c}}^{1 / 128}$

where $h_{\mathrm{c}}$ is the contact depth of the indentation and the subscript "c" refers to contact. $h_{\mathrm{c}}$ can be determined by means of the following expression:

$h_{\mathrm{c}}=h_{\max }-\varepsilon \frac{P_{\max }}{S}$

where $\varepsilon \approx 0.75$ for a parabolic tip, and $h_{\max }$ and $P_{\max }$ are the maximum depth and peak load, respectively.

The contact stiffness, i.e. the initial unloading slope, can be derived from the unloading curve which obeys the simple power law

$P=\alpha\left(h-h_{\mathrm{f}}\right)^{m}$

where $\alpha, m$ are fitting constants and $h_{\mathrm{f}}$ is the residual depth after complete unloading. The values of $\alpha, m$ and $h_{\mathrm{f}}$ can be empirically determined by fitting the unloading data. Thus the contact stiffness can be easily derived from

$S=\left(\frac{\mathrm{d} P}{\mathrm{~d} h}\right)_{h=h_{\max }}=\alpha m\left(h-h_{f}\right)^{m-1}$

Eqs. (2)-(7) reflect the analysis procedure of the O-P method [2].
One finds using Eqs. (2)-(7), that the measured indentation modulus for alumina is almost always higher than its value of $420 \mathrm{GPa}$ (Table 1) [2,19-21]. Krell and Schadlich indicated that, in sapphire oriented in the $\langle 1210\rangle$ direction and tested by Vickers indentation, the slopes of the initial unloading curves define a wide range of Young's modulus, i.e. $390-475 \mathrm{GPa}$ [19]. In the frame of the O-P method, Zeng and Chiu [20] determined the Young's modulus of alumina to $474 \pm 41.3 \mathrm{GPa}$, much higher than the above reference value of $420 \mathrm{GPa}$. Again by nanoindentation and via the $\mathrm{O}-\mathrm{P}$ method, Twigg et al. [21] reported a Young's modulus of a polycrystalline alumina of $458 \pm 75 \mathrm{GPa}$. By means of a Berkovich indenter, Oliver and Pharr measured $441 \pm 4.7 \mathrm{GPa}$ for $(0001)$ sapphire, a value significantly higher than the Voigt/Reuss average of $403 \mathrm{GPa}[2,22]$. Such a high Young's modulus for alumina is likely to have resulted from its elastic anisotropic response to nanoindentation. For elastically anisotropic materials, $S$ is written as [23]

$S=\frac{2}{\sqrt{\pi}} M_{\text {real }} A_{\text {real }}^{1 / 2}$

where $M_{\text {real }}$ is the reduced modulus; $A_{\text {real }}$ is the real projected area of the indentation. Swadener and Pharr concluded that a range of Young's modulus for sapphire is between $410-440 \mathrm{GPa}$ depending on $A_{\text {real }}$ which actually changes between two extreme values depending on the orientation of the contact surface [23].

\section{Experimental results}

\subsection{Loading-unloading curves and tip location}

The recorded load-depth curves and their initial curvatures at unloading, i.e. the various contact stiffnesses, may be affected by local heterogeneities such as grain orientations or the various phases $[2,10]$. Fig. 2 presents the load-depth curves, for $P_{m}=15 \mathrm{mN}$, recorded at two different locations of both alumina and its composite containing 5 vol. \% of SiC particles. Under the given load, the indentation depth in the alumina sample is almost unchanged whereas the stiffness, the values of $m$ and $\alpha$ as well as the Young's modulus differ quite substantially from one location to the other. As shown in Fig. 2a, the value of $435 \mathrm{GPa}$ for the Young's modulus is consistent with that taken from the literature, whereas that of $510 \mathrm{GPa}$ is significantly higher. Since the elastic response of sapphire is crystal orientation dependent, the latter, rather high value of 


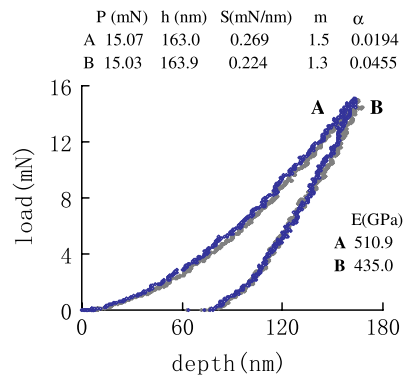

Fig. 2a. P-h curves recorded at two different locations under $P_{\mathrm{m}}=15 \mathrm{mN}$ for $\alpha-\mathrm{Al}_{2} \mathrm{O}_{3}$.

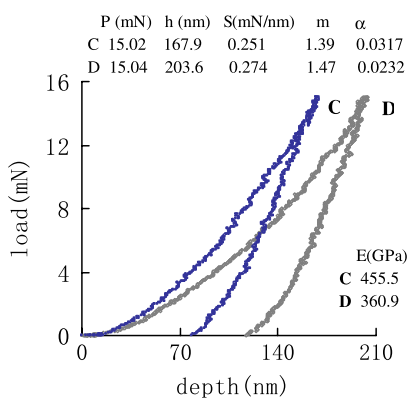

Fig. 2b. P-h curves recorded at two different locations under $P_{\mathrm{m}}=15 \mathrm{mN}$ for $\alpha-\mathrm{Al}_{2} \mathrm{O}_{3} / \mathrm{SiC}(5 \%)$.

the Young's modulus may result from an indentation oriented near the $c$-axis $[2,22]$. As to the composite, the indentations at two locations under the same load level exhibit different depths, $167.9 \mathrm{~nm}$ and $203.6 \mathrm{~nm}$, consistent with two different phases having been indented, the phase with the shallower indentation being the hardest of both (Fig. 2b). Although the difference in stiffness is not pronounced, the fitting parameters of the two curves are clearly different. The values of $m$ and $\alpha$ are 1.39 and 0.0317 for the harder and, 1.47 and 0.0232 for the softer, respectively. The corresponding Young's moduli are 456 and $361 \mathrm{GPa}$. The latter value of $361 \mathrm{GPa}$ is much lower than those of the two solid phases, $\mathrm{Al}_{2} \mathrm{O}_{3}$ and $\mathrm{SiC}$, taken separately (Table 1). We believe that this is due to the probing being achieved at especially soft locations of the composite such as pores or interfaces. On the other hand, a Young's modulus amounting to $456 \mathrm{GPa}$ is consistent with the indentation of either one of the two solid phases. Under the present experimental circumstances, it seems not feasible to discriminate between $\mathrm{Al}_{2} \mathrm{O}_{3}$ and $\mathrm{SiC}$ as the response of $\mathrm{Al}_{2} \mathrm{O}_{3}$ to indentation is quite sensitive to the crystal orientation which is unknown during the test.

\subsection{Contact stiffness $S$ and the parameters $m$ and $\alpha$}

Fig. 3a shows the relationships between the contact stiffness, $S_{\mathrm{O}-\mathrm{P}}$ calculated using the O-P method, and the contact depth. The experimental scatter reflected by the error bars, vary with the penetration depth for all the tested materials. Fine details in Fig. 3a are better represented in

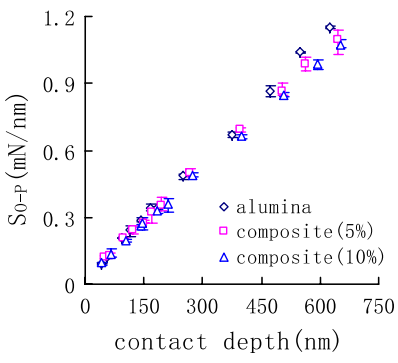

Fig. 3a. Plots of $S_{\mathrm{O}-\mathrm{P}-} h_{\mathrm{c}}$ for the tested materials (contact depth: 0 $750 \mathrm{~nm})$.

the magnified part of Fig. 3b for contact depths less than $300 \mathrm{~nm}$, showing that it is the contact stiffness of the composite containing $5 \%$ of $\mathrm{SiC}$ particles which displays the largest dispersion of all three materials.

The contact stiffness determined using Eq. (7) is related to the parameters $m$ and $\alpha$. As shown in Fig. 4a, the $m$-values vary within $1.25-1.55$ for $\mathrm{Al}_{2} \mathrm{O}_{3}, 1.18-1.6$ for $\mathrm{Al}_{2} \mathrm{O}_{3} /$ $\mathrm{SiC}(5 \%)$ and $1.15-1.7$ for $\mathrm{Al}_{2} \mathrm{O}_{3} / \mathrm{SiC}(10 \%)$. Large scatters of $m$ are associated with contact depths less than $300 \mathrm{~nm}$ for all three materials. For depths exceeding $300 \mathrm{~nm}$, the scatter in single-phase $\mathrm{Al}_{2} \mathrm{O}_{3}$ is small relative to those obtained in the two composites. The mean $m$-values are $1.42 \pm 0.05, \quad 1.44 \pm 0.08$ and $1.43 \pm 0.07$ for $\mathrm{Al}_{2} \mathrm{O}_{3}$, $\mathrm{Al}_{2} \mathrm{O}_{3} / \mathrm{SiC}(5 \%)$ and $\mathrm{Al}_{2} \mathrm{O}_{3} / \mathrm{SiC}(10 \%)$, respectively. Additionally, the $m$-values can be reasonably thought of as constant beyond a certain contact depth of approximately $300 \mathrm{~nm}$ (Fig. 4a). Plots of $\alpha$-values versus peak load are presented in Fig. 4b. As shown in Eq. (6), the parameter $\alpha$ is critically sensitive to the indentation depth, resulting

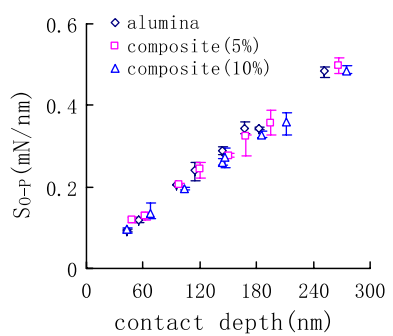

Fig. 3b. Plots of $S_{\mathrm{O}-\mathrm{P}}-h_{\mathrm{c}}$ for the tested materials (contact depth: 0 $300 \mathrm{~nm})$.

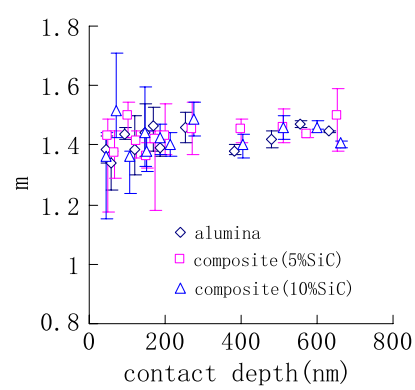

Fig. 4a. Plots of $m-h_{\mathrm{c}}$ for the tested materials. 


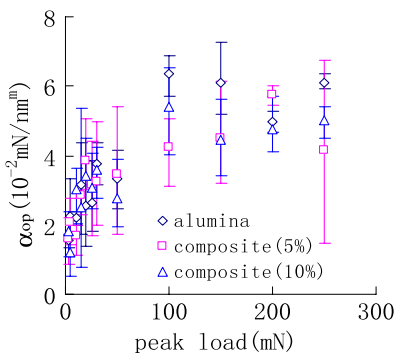

Fig. 4b. Plots of $\alpha$-peak load for the tested materials.

in serious experimental scatter. Despite such scatters, the mean $\alpha$-values exhibit clear trends upon increasing the load level for all tested materials provided load levels are less than $100 \mathrm{mN}$. The values of $m$ and $\alpha$ conform to the analysis of Pharr and Bolshakov [24], where the power law exponent $m$ is a constant while the power law coefficient $\alpha$ increases with contact penetration depth for a given material.

As argued above in discussing the loading-unloading behavior, it is quite likely that the large scatters of both $m$ and $\alpha$ reflect the heterogeneous microstructures of the volume of material probed, which we will discuss later in more detail.

\subsection{Young's modulus}

Using the Poisson's ratio of 0.23 for all the tested materials and taking $E_{i}=1141 \mathrm{GPa}$ and $v_{i}=0.07$ for the diamond indenter tip, the Young's modulus of each tested material can be calculated based on the experimentally determined value of $E_{\mathrm{r}}$. The Young's moduli determined with the $\mathrm{O}-\mathrm{P}$ method for alumina $\mathrm{Al}_{2} \mathrm{O}_{3}$ and both composites is presented in Fig. 5a. Upon increasing the contact depth, the modulus of alumina $\mathrm{Al}_{2} \mathrm{O}_{3}$ varies within 395-

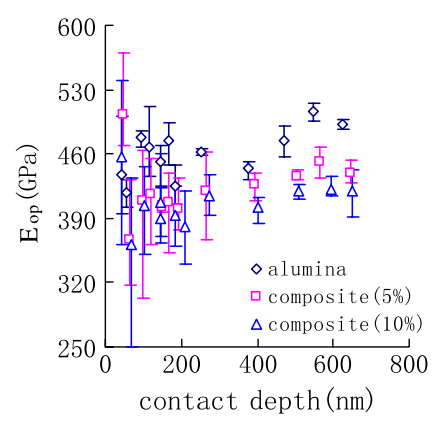

Fig. 5a. $E_{\mathrm{O}-\mathrm{P}}$ against contact depth for the tested materials.
$515 \mathrm{GPa}$. Large scatters again result from contact depths less than $300 \mathrm{~nm}$. The Young's modulus of $\mathrm{Al}_{2} \mathrm{O}_{3} /$ $\mathrm{SiC}(5 \%)$ is within the range of $300-570 \mathrm{GPa}$ whereas that of $\mathrm{Al}_{2} \mathrm{O}_{3} / \mathrm{SiC}(10 \%)$ is within $250-540 \mathrm{GPa}$. Similarly, the moduli probed in both composites exhibit larger scatters when the contact depth is less than $300 \mathrm{~nm}$.

For clarity the detailed testing data and the resultant moduli are summarised in Table 2. In alumina, the highest Young's modulus, $515 \mathrm{GPa}$, was probed at a contact depth of $543.4 \mathrm{~nm}$ under a peak load of $200 \mathrm{mN}$. The minimum Young's modulus probed in this material, $395 \mathrm{GPa}$, was obtained at a contact depth of $43.2 \mathrm{~nm}$ under $3 \mathrm{mN}$. For the two composites, the highest Young's moduli, which are 569 and $539 \mathrm{GPa}$ for $\mathrm{Al}_{2} \mathrm{O}_{3} / \mathrm{SiC}(5 \%)$ and $\mathrm{Al}_{2} \mathrm{O}_{3} /$ $\mathrm{SiC}(10 \%)$ respectively, corresponded to contact depths of $40-42 \mathrm{~nm}$ under $3 \mathrm{mN}$. The lowest Young's modulus in the composites, $303 \mathrm{GPa}$, was probed at $140 \mathrm{~nm}$ under $10 \mathrm{mN}$ for $\mathrm{Al}_{2} \mathrm{O}_{3} / \mathrm{SiC}(5 \%)$ while a modulus of $250 \mathrm{GPa}$ was probed in $\mathrm{Al}_{2} \mathrm{O}_{3} / \mathrm{SiC}(10 \%)$ at $77 \mathrm{~nm}$ under $5 \mathrm{mN}$. In both composites, those lower than $395 \mathrm{GPa}$ were obtained from contact depths less than $300 \mathrm{~nm}$.

From the data in Tables 1 and 2, it is reasonable to assume that the Young's modulus probed in the alumina matrix of both composites should not be lower than $395 \mathrm{GPa}$. As the maximum and minimum moduli of the composites were probed at penetration depth less than $300 \mathrm{~nm}$ (Table 2), it can be concluded that the maximum and the minimum moduli were probed in non-equivalent locations of the composites. In other words, the maximum values were probed at alumina and/or $\mathrm{SiC}$ phases while the minimum values $(E<395 \mathrm{GPa})$ should correspond with pores (and/or interfaces) dispersed within the contact depth of less than $300 \mathrm{~nm}$.

The Young's modulus estimates have been summarized in Table 3. $E_{\mathrm{O}-\mathrm{P}}$ is the average modulus obtained with the $\mathrm{O}-\mathrm{P}$ method under peak loads between 3 and $250 \mathrm{mN}$, and $E^{\prime}{ }_{\text {O-P }}$ is the average of those moduli greater than $395 \mathrm{GPa}$ in the composites, i.e. those associated with either alumina or $\mathrm{SiC}$ grains. For alumina, $E_{\mathrm{O}-\mathrm{P}}$ is the same as $E_{\mathrm{O}-\mathrm{P}}^{\prime}$ and has the average value of $461 \mathrm{GPa}$ with a standard deviation of $18 \mathrm{GPa}$. This average value of $461 \mathrm{GPa}$ for alumina is greater than that of 420 in Table 1 but consistent with the results reported on the Young's modulus probed by the O-P method [2,19-21]. For the two composites, the magnitudes of $E_{\mathrm{O}-\mathrm{P}}$ are $423 \mathrm{GPa}$ with a standard deviation of $32 \mathrm{GPa}$ for $\mathrm{Al}_{2} \mathrm{O}_{3} / \mathrm{SiC}(5 \%)$ and $406 \mathrm{GPa}$ with a standard deviation of $34 \mathrm{GPa}$ for $\mathrm{Al}_{2} \mathrm{O}_{3} / \mathrm{SiC}(10 \%)$. These standard deviations are larger than the standard deviation obtained for alumina. In $\mathrm{Al}_{2} \mathrm{O}_{3} / \mathrm{SiC}(5 \%)$ and $\mathrm{Al}_{2} \mathrm{O}_{3} / \mathrm{SiC}(10 \%)$, how-

Table 2

Maximum, minimum modulus, load levels and contact depths for tested materials

\begin{tabular}{llllll}
\hline Material & $E_{\max }(\mathrm{GPa})$ & $P(\mathrm{mN}) ; h_{\mathrm{c}}(\mathrm{nm})$ & $E_{\min }(\mathrm{GPa})$ & $P(\mathrm{mN}) ; h_{\mathrm{c}}(\mathrm{nm})$ & $h_{\mathrm{c}}(\mathrm{E}<395 \mathrm{GPa})$ \\
\hline$\alpha-\mathrm{Al}_{2} \mathrm{O}_{3}$ & 515 & 200,543 & 395 & 3,43 & 0 \\
$\alpha-\mathrm{Al}_{2} \mathrm{O}_{3} / \mathrm{SiC}(5 \%)$ & 569 & 3,41 & 303 & 10,141 & $h_{\mathrm{c}}<290 \mathrm{~nm}$ \\
$\alpha-\mathrm{Al}_{2} \mathrm{O}_{3} / \mathrm{SiC}(10 \%)$ & 539 & 3,42 & 249 & $5.02,77$ & $h_{\mathrm{c}}<270 \mathrm{~nm}$ \\
\hline
\end{tabular}


Table 3

Young's modulus (GPa) got in the tested materials

\begin{tabular}{|c|c|c|c|c|c|c|c|c|}
\hline \multirow[t]{2}{*}{ Material $(v=0.23)$} & \multirow[t]{2}{*}{$E_{\mathrm{O}-\mathrm{P}}(\gamma=1.034)$} & \multirow[t]{2}{*}{$E_{\mathrm{O}-\mathrm{P}}^{\prime}(>395)$} & \multicolumn{3}{|c|}{$E_{\text {Alumina }}=420 ; E_{\mathrm{SiC}}=460$} & \multicolumn{3}{|c|}{$\underline{E_{\text {Alumina }}}=460 ; E_{\mathrm{SiC}}=460$} \\
\hline & & & $E_{\text {pre }}^{(9)}$ & $E_{\text {pre }}^{(10)}$ & $E_{\text {pre }}^{(11)}$ & $E_{\text {pre }}^{(9)}$ & $E_{\text {pre }}^{(10)}$ & $E_{\text {pre }}^{(11)}$ \\
\hline $\mathrm{Al}_{2} \mathrm{O}_{3}$ & $461 \pm 18$ & $461 \pm 18$ & 417 & 417 & 419 & 457 & 457 & 458 \\
\hline $\mathrm{Al}_{2} \mathrm{O}_{3} / \mathrm{SiC}(5 \%)$ & $423 \pm 32$ & $442 \pm 18$ & 378 & 383 & 402 & 412 & 416 & 437 \\
\hline $\mathrm{Al}_{2} \mathrm{O}_{3} / \mathrm{SiC}(10 \%)$ & $406 \pm 34$ & $433 \pm 16$ & 371 & 377 & 400 & 403 & 406 & 431 \\
\hline
\end{tabular}

ever, $E_{\text {O-P }}^{\prime}$ has average values of $442 \mathrm{GPa}$ with a standard deviation of $18 \mathrm{GPa}$ and $433 \mathrm{GPa}$ (standard deviation $16 \mathrm{GPa}$ ), respectively. The average moduli become higher while the standard deviations decrease. This is ascribed to the elimination of the influence of the pores in the vicinity of an indentation surface with contact depth less than $300 \mathrm{~nm}$. Plots of $E_{\text {O-P }}^{\prime}$ against contact depth for all three tested materials are presented in Fig. 5b.

The Young's modulus of a porous sample, $E$, can be pre-estimated based on models proposed by Phani [25], Duckworth [26] and Wang [27]

$E=E_{0}(1-a p)^{n}$

$E=E_{0} \mathrm{e}^{-b_{1} p}$

$E=E_{0} \mathrm{e}^{-\left(b_{2} p+c p^{2}\right)}$

where $E_{0}$ is the Young's modulus of the fully dense reference material, $p$ is the porosity and the coefficients $n, a$, $b_{1}, b_{2}$ and $c$ depend on pore shape and porosity. In the present tests, $n=2, a=3.85$ [25] for lower porosity; $b_{1}=7$ [26]; and $b_{2}=0.946, c=2.54$ [27] for the highest values of $E / E_{0}$. The estimated Young's modulus ( $E$ in Eqs. (9)-(11)) is denoted as $E_{\text {pre }}$ in Table 3, in which the superscript (9), (10) and (11) are the numbers of equations used for calculations. In the composite materials the values of $E_{0}$ were calculated according to the law of mixtures based both phases of alumina and SiC. For fully dense alumina, $E_{\text {alumina }}=420$ and $460 \mathrm{GPa}$ are used and the former value is provided in the literature [17] and the latter is obtained in the present tests as well as in previous investigations using the O-P method [19-21]. On the other hand, $E_{\mathrm{SiC}}=460$ $\mathrm{GPa}$ is used for SiC particles [17].

In Table 3, the first group of pre-estimated moduli is based on $E_{\text {alumina }}=420 \mathrm{GPa}$ and $E_{\mathrm{SiC}}=460 \mathrm{GPa}$, while the second group corresponds to $E_{\text {alumina }}=460 \mathrm{GPa}$ and

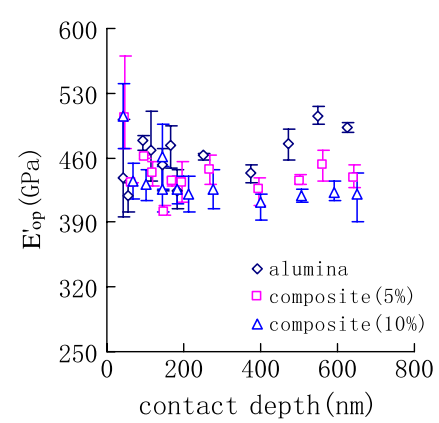

Fig. 5b. $E_{\mathrm{O}-\mathrm{P}}^{\prime}$ against contact depth for the tested materials.
$E_{\mathrm{SiC}}=460 \mathrm{GPa}$. Obviously, resultant moduli for both composites in the second group are higher than those in the first group due to the higher modulus of the alumina. In the second group, the moduli pre-estimated by Eqs. (9) and (10) are close to the experimental value $E_{\mathrm{O}-\mathrm{P}}$ for both composites. Those obtained using Eq. (11) agree quite well with the values of $E^{\prime}$ O-P. As Eq. (11) is suitable to solids with isolated closed pores [27], good agreement again indicates that the modulus $E_{\text {O-P }}^{\prime}$ probed in both composites is not influenced by the pores dispersed in the vicinity of an indentation surface.

\section{Discussion}

\subsection{Effect of microstructure length scales}

As mentioned earlier, the significant scatters in both $m, \alpha$ and in the Young's modulus, for contact depths less than a certain value, reflect the material heterogeneity.

To further understand microstructure scale effects in indentation tests, several meaningful microstructurerelated parameters of the tests are showed in Table 4. In the table, $h_{\min }$ is the contact depth at which the maximum Young's modulus was obtained. $\delta_{I \min }$ is the apparent size of the projected area of an indentation at $h_{\mathrm{min}} . \delta_{I 0}$ is the apparent size of the projected area at a specific depth, $h_{0}$, at which the minimum Young's moduli were probed in the tested materials. $\delta_{\mathrm{SiC}}$ is the mean distance between two nearest-neighbouring particles for the composites. $h_{\max }$ is the maximum contact depth reached.

The $m$ - and $\alpha$-values, derived from the loading-unloading curves, are sensitive to the depth and position of the indentation. According to Table 1, in an alumina grain 5 microns in size for both composites, the $\mathrm{SiC}$ particle size is about $100 \mathrm{~nm}$ and the distance between two nearest $\mathrm{SiC}$ particles is within $150-240 \mathrm{~nm}$ (Table 1). Since shallow indentations can be located in the matrix, close to a $\mathrm{SiC}$ particle, or at a $\mathrm{SiC}$ particle as well as at pores, local heterogeneous microstructures around the indentation result in inherently large scatters. Thus $m$-values exhibit larger dispersion for depths less than $300 \mathrm{~nm}$ (Fig. 4a). The scatter on the value of the $\alpha$ is not as serious in alumina since this is expected to depend essentially on grain orientation as well as on the presence of interfaces within a relatively large-grained material (grain size of about $2 \mu \mathrm{m}$ ).

A significant dispersion on the Young's modulus can also be understood from the correlation between the penetration depth and the microstructure length scale of the 
Table 4

Important scales in current nanoindentation tests and the tested materials

\begin{tabular}{|c|c|c|c|c|c|c|}
\hline Material & $h_{\min }(\mathrm{nm})$ & $\delta_{I \min }(\mathrm{nm})$ & $\delta_{\mathrm{SiC}}(\mathrm{nm})$ & $h_{0}(E<395)$ & $\delta_{I 0}(\mathrm{~nm})$ & $h_{\max }(\mathrm{nm})$ \\
\hline$\alpha-\mathrm{Al}_{2} \mathrm{O}_{3}$ & 543 & $2 h_{\min }-3 h_{\min }$ & $d_{\text {grain }}=2000$ & 43 & $2 h_{0}-3 h_{0}$ & 630 \\
\hline$\alpha-\mathrm{Al}_{2} \mathrm{O}_{3} / \mathrm{SiC}(5 \%)$ & 41 & $82-122$ & 242 & 141 & $2 h_{0}-3 h_{0}$ & 670 \\
\hline$\alpha-\mathrm{Al}_{2} \mathrm{O}_{3} / \mathrm{SiC}(10 \%)$ & 42 & $84-126$ & 147 & 77 & $2 h_{0}-3 h_{0}$ & 650 \\
\hline
\end{tabular}

tested materials. For the composite containing $10 \mathrm{vol} . \%$ of $\mathrm{SiC}$ particles, the mean distance between two nearestneighbouring particles lies between 88 and $147 \mathrm{~nm}$. Since at an initial contact depth of $40 \mathrm{~nm}$, the apparent size of the projected area of an indentation is $2-3 h_{\min }$, i.e. 80 $120 \mathrm{~nm}$, the tip may not meet any particle at all or else it can meet one SiC particle in the depth direction and two particles in the direction along the contact surface at maximum. As $\mathrm{SiC}$ particles should introduce further weak interfaces, differences in the number of the $\mathrm{SiC}$ particles or pores can also create large scatters at shallow depths. For example, the maximum modulus value measured at a depth of about $40 \mathrm{~nm}$ indicates that the tip must have indented either the alumina phase (between two SiC particles) or a SiC particle but no pores. By contrast, the minimum modulus value ( $<395 \mathrm{GPa}$ ) was probed at or close to a pore or a weak interface between a $\mathrm{SiC}$ particle and alumina.

It should be emphasized though that the maximum moduli probed for $\mathrm{Al}_{2} \mathrm{O}_{3} / \mathrm{SiC}(5 \%)$ and $\mathrm{Al}_{2} \mathrm{O}_{3} / \mathrm{SiC}(10 \%)$ are 569 and $540 \mathrm{GPa}$, respectively, thus greater than the maximum modulus detected in alumina, $515 \mathrm{GPa}$. The contact depth at which the maximum moduli were probed is about $40 \mathrm{~nm}$ for the composites and $543 \mathrm{~nm}$ for $\mathrm{Al}_{2} \mathrm{O}_{3}$. It is worth noting that at shallow depths, the measurements become substantially sensitive to surface roughness [2]. In the present experiments, for $\mathrm{Al}_{2} \mathrm{O}_{3}, \mathrm{Al}_{2} \mathrm{O}_{3} / \mathrm{SiC}(5 \%)$ and $\mathrm{Al}_{2} \mathrm{O}_{3} / \mathrm{SiC}(10 \%)$ surface roughness is 42,80 and $48 \mathrm{~nm}$, respectively, so that the $40 \mathrm{~nm}$ contact depth for the two composites is clearly within their surface roughness influential range.

As the applied load increases, the correlation between the contact depth and the microstructure typical length scale becomes more profound. For the composite $\mathrm{Al}_{2} \mathrm{O}_{3} /$ $\mathrm{SiC}(5 \%)$, the maximum contact depth, $h_{\max }$, is of the order of $4 \times \delta_{\mathrm{SiC}}$ for small $\mathrm{SiC}$ particles or $3 \times \delta_{\mathrm{SiC}}$ for large particles, as shown in Table 4. Along the depth direction, this would correspond with an average of either 3 small particles or 2 large particles. However, at such depths, the apparent size of the projected contact area on the surface, $\delta_{I \max }$, is equal to $2-3 h_{\max } \approx 8-12 \delta_{\mathrm{SiC}}$ and $6-9 \delta_{\mathrm{SiC}}$ for small and large particles, respectively. This is equivalent to saying that either 7-11 small particles or 5-8 large particles, respectively, can be involved in projection. The moduli probed at depths between 300 and $700 \mathrm{~nm}$ do not exhibit larger scatters than those at depths less than $300 \mathrm{~nm}$ (Fig. 5a). It should be kept in mind that in fact, the elastic modulus probed by indentation is related to the elastic deformation in a field beneath the indentation $[2,28]$. This field can be approximated by a hemispherical zone around the indentation trace [11]. The size of this area around the hemispherical zone is evidently larger than that embodied by the indentation trace. With increasing the load, both the hemispherical area and the surrounding zone expand thus involving more $\mathrm{SiC}$ particles. Hence, as the contact depth increases, the density of $\mathrm{SiC}$ particles and pores actually interacting with the load ceases to fluctuate to adjust to the expected statistical value, therefore resulting in a smaller scatter. The critical penetration depth at which the transition occurs is estimated to $300-700 \mathrm{~nm}$. In other words, the elastic modulus probed within the 300-700 nm depth range should combine the responses of the alumina and $\mathrm{SiC}$ phases as well as of the pores in an averaged depthindependent manner. The test data corresponding to the composite $\mathrm{Al}_{2} \mathrm{O}_{3} / \mathrm{SiC}(10 \%)$ can be analysed in the same way.

It is worth emphasizing that the modulus $E^{\prime}{ }_{\mathrm{O}-\mathrm{P}}$ (Fig. $5 \mathrm{~b}$ ) does not include pores at contact with the indenter tip but corresponds to the combined responses of the matrix, $\mathrm{SiC}$ particles and isolated pores in the volume around the indentation. Thus $E_{\mathrm{O}-\mathrm{P}}^{\prime}$ represents bulk elastic properties of the composite, and it is consistent with that predicted by Eq. (11). However, as shown in Fig. 5b, scatters also could be seen in $E_{\mathrm{O}-\mathrm{P}}^{\prime}$ against contact depth.

\subsection{Effects of grain orientation}

The Young's modulus of alumina, $E_{\mathrm{O}-\mathrm{P}}$, measured in the present tests amounts to $461 \mathrm{GPa}$ with a standard deviation of $18 \mathrm{GPa}$ and it is higher than the value of $420 \mathrm{GPa}$ in Table 1. Similar results have been reported based on the analysis of the initial slopes of unloading curves in nanoindentation tests [2,19-21]. Clearly elastic anisotropy plays a perceivable role in this type of measurement which can be explained based on the study of Swadener and Pharr [23] (see Section 2.2). Eq. (8), which is taken from this work, describes the elastic response to indentations in highly elastic anisotropic materials. This equation can be rewritten for indentation experiments as

$S=\frac{2}{\sqrt{\pi}} M_{\exp } A_{\exp }^{1 / 2}$

where $A_{\exp }$ is the projected area (given by Eq. (4) [2]) and $M_{\text {exp }}$ is the reduced modulus obtained for current tested material. Using Swadener and Pharr's mean value of the indentation modulus, 410-440GPa, and given the value of $S$ determined experimentally, we can compare the reduced modulus $M_{\exp }$ to that for sapphire, $M_{\text {real }}$ [23]. 
$M_{\text {exp }} / M_{\text {real }}$, plotted against contact depth for alumina in Fig. 6, is larger than 1 in most cases, which indicates that the true projected area $A_{\text {real }}$ is larger than $A_{\text {exp }}$. It should be kept in mind that the parameters entering Eq. (4) for $A_{\text {exp }}$ were calibrated on a standard isotropic material, which may correspond with smaller projected areas in anisotropic materials, thus explaining why the magnitude of the indentation modulus of alumina in the current tests is higher than those in found in the literature $[17,23]$.

We now address the origin of the scatter in the modulus $E^{\prime}{ }_{\text {O-P }}$ (Fig. 5b and Table 3) and how this scatter relates to microstructure heterogeneities for each tested materials. For sapphire, Swadener and Pharr [23] showed that the Young's modulus lies within 410-440 GPa. The maximum and minimum values should depend on the orientation of the indentation axis, i.e. parallel or perpendicular to the $c$-axis, which yields a standard deviation of $\pm 15 \mathrm{GPa}$. As shown in Table 3, however, the moduli of $E_{\mathrm{O}-\mathrm{P}}^{\prime}$, $461 \pm 18 \mathrm{GPa}$ for alumina exhibits a nearly constant deviation. This is entirely consistent with the indentations having been made in distinct single grains (Fig. 5b). The standard deviation (Table 3 ) of $\pm 18 \mathrm{GPa}$ for alumina is close to that of sapphire, $\pm 15 \mathrm{GPa}$, previously estimated by Swadener and Pharr [23]. It is normal that standard deviations are larger in alumina than in sapphire because of structural inhomogeneities, such as grain boundaries. Fig. 7 shows the normalized standard deviation of $E_{\text {O-P }}^{\prime}$ (SD) under varied contact depth for the tested materials, and the dashed line is for sapphire taken from the reference

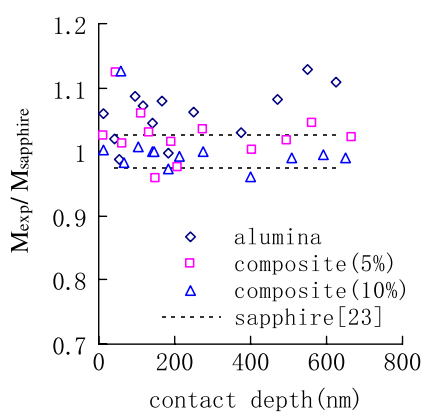

Fig. 6. Plots of normalized M-contact depth for the tested materials, the dashed for the sapphire [23].

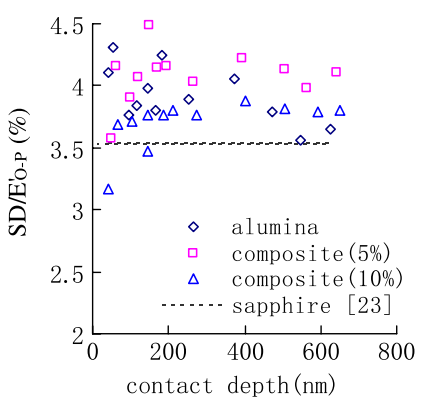

Fig. 7. Plots of normalized SD-contact depth for the tested materials, the dashed for the sapphire [23].
[23]. The average normalized SD, 3.9\% for alumina, is higher than that for sapphire, 3.5\% [23].

In both composites, besides influence of crystalline orientation of alumina, influence from different phases, alumina and SiC particles, existed. As shown in Table 1, the difference in Young's modulus between alumina and $\mathrm{SiC}$ particles is about $40 \mathrm{GPa}$ [17] approaching the dispersion expected from crystalline orientation in sapphire. In Fig. 5b and Table 3, the scatters on $E_{\text {O-P }}^{\prime}$ for both composites are the same as that of alumina with standard deviations amounting to $\pm 18, \pm 16 \mathrm{GPa}$ for alumina/SiC $(5 \%)$ and alumina/ $\mathrm{SiC}(10 \%)$, respectively. These deviations are also actually close to the variability expected from crystalline orientation [23]. This is why it is difficult to tell which part of the deviation comes from crystalline orientation of alumina or other phase in both composites. Anyway, all above has attested that scatters and standard deviation of $E^{\prime}{ }_{\mathrm{O}-\mathrm{P}}$ reflect intrinsic variability of the tested materials.

\section{Conclusions}

The Oliver-Pharr method was employed to analyse nanoindentation data of ceramic composites, $\mathrm{Al}_{2} \mathrm{O}_{3} / \mathrm{SiC}_{p}(5 \%)$ and $\mathrm{Al}_{2} \mathrm{O}_{3} / \mathrm{SiC}_{p}(10 \%)$, and alumina $\mathrm{Al}_{2} \mathrm{O}_{3}$. The following conclusions have been deduced:

1. Both the power law exponent $m$ and the power law coefficient $\alpha$ in unloading curves of indentations can reflect partly elastic responses of heterogeneous microstructures around an indentation thus both parameters present large scatters at a contact depth less than $300 \mathrm{~nm}$.

2. A detailed analysis of the relationship between length scales related to the microstructure of the composites and the indentation process explains why the Young's moduli determined at contact depths less than $300 \mathrm{~nm}$ exhibit larger scatters than those obtained at depths greater than $300 \mathrm{~nm}$. Taking into account the microstructure effects, the resulting Young's moduli could be predicted with the given models quite well.

3. Further analysis has been applied to the dispersion of the Young's moduli of alumina $\mathrm{Al}_{2} \mathrm{O}_{3}$ and its composites. It indicates that the scatters as well as deviations reflect the intrinsic variability of the tested materials, such as different phases and pores, interfaces etc... In particular, the standard deviation of $E^{\prime}{ }_{\mathrm{O}-\mathrm{P}}$ is almost owing to the influence of elastic anisotropy of the tested alumina to nanoindentations.

\section{Acknowledgement}

This work is financially supported by National Natural Science Foundation of China (Grant No.10472120) and Chinese Academy of Sciences (Grant No.KJCX2-SW-L2 and KJCX2-YW-M04). The authors wish to thank the referees for their helpful review of our work. 


\section{References}

[1] Doerner MF, Nix WD. A method for interpreting the data from depth-sensing indentation instruments. J Mater Res 1986;1:601-9.

[2] Oliver WC, Pharr GM. An improved technique for determining hardness and elastic modulus using load and displacement sensing indentation. J Mater Res 1992;7(6):1564-83.

[3] Zheng CM, Zheng YT. On the initial unloading slope in indentation of elastic-plastic solids by an indenter with an axisymmetric smooth profile. Appl Phys Lett 1997;71:2623-5.

[4] Nix WD. Elastic and plastic properties of thin films on substrates: nano-indentation techniques. Mat Sci Eng 1997;A234-236:37-44.

[5] Giannakopouls AE, Suresh S. Determination of elastoplastic properties by instrumented sharp indentation. Scripta Mater 1999;40(10):1191-8.

[6] Pharr GM. Measurement of mechanical properties by ultra-low load indentation. Mater Sci Eng 1998;A253:151-9.

[7] Alcal' AG et al. Mechanical properties of amorphous anodic alumina and tantala films using nanoindentation. Nanotechnology 2002;13:451-5.

[8] Krell A, Schadlich S. Nanoindentation hardness of submicormeter alumina ceramics. Mater Sci Eng 2001;A307:172-81.

[9] Fan $\mathrm{Z}$ et al. Anisotropic properties of human tibial cortical bone as measured by nanoindentation. J Orthopaedic Res 2002;20:806-10.

[10] Ling $\mathrm{Z}$. Nano-microscale characterizations to $\mathrm{Al}_{2} \mathrm{O}_{3} / \mathrm{SiC}_{\text {nano }}$ ceramic composites. Int J Non Sci Num Simulation 2002;SI3(3-4):487-90.

[11] $\mathrm{Hu} \mathrm{XZ,} \mathrm{Lawn} \mathrm{BR.} \mathrm{A} \mathrm{simple} \mathrm{indentation} \mathrm{stress-strain} \mathrm{relation} \mathrm{for}$ contacts with spheres on bilayer structures. Thin Solid Films 1998;322:225-32.

[12] Jung YG et al. Evaluation of elastic modulus and hardness of thin films by nanoindentation. J Mater Res 2004;19(10):3076-80.

[13] Gong JH et al. J Eur Ceram Soc 2005;25:649-54.
[14] Niihara K. New design concept of structural ceramics-ceramic nanocomposite. J Ceram Soc Jpn 1991;99(10):974-82.

[15] Zhao $\mathbf{J}$ et al. Mechanical behavior of alumina-silicon carbon "Nanocomposites". J Am Ceram Soc 1993;76(2):503-10.

[16] Roy GLE et al. Model of ductile fracture based on the nucleation and growth of voids. Acta Metall 1981;29(13):1509-22.

[17] NIST Structural Ceramics Database (SCD), <http:// www.ceramics.nist.gov $>$.

[18] Jung YG et al. Strength of silicon, sapphire and glass in the subthreshold flaw region. Acta Mater 2004;52:3459-66.

[19] Krell A, Schadlich S. Nanoindentation hardness of submicormeter alumina ceramics. Int J Refract Metals Mater 2001;19:237-43.

[20] Zeng K, Chiu Ch. An analysis of load-penetration curves from instrumented indentation. Acta Mater 2001;49:3539-51.

[21] Twigg PC et al. Nanoindentation investigation of micro-fracture wear mechanisms in polycrystalline alumina. $J$ Mater Sci 2002;37:845-53.

[22] Simmons G, Wang H. Single crystal elastic constants and calculated aggregate properties: A handbook. 2nd ed. Cambridge (MA): The MIT Press; 1971.

[23] Swadener JG, Pharr GM. Indentation of elastically anisotropic halfspaces by cones and parabolae of revolution. Phil Mag 2001;A81(2):447-66.

[24] Pharr GM, Bolshakov A. Understanding nanoindentation unloading curves. J Mater Res 2002;17:2660-71.

[25] Phani KK. Young's modulus-porosity relation in gypsum systems. Am Ceram Bull 1986;65(12):1584-6.

[26] Duckworth W. Discussion on compression strength of porous sintered $\mathrm{Al}_{2} \mathrm{O}_{3}$ and $\mathrm{ZrO}$. J Am Ceram Soc 1953;36:68.

[27] Wang JC. Young's modulus of porous materials (Parts I, II). J Mater Sci 1984;19:801-14.

[28] Johnson KL. Contact mechanics. Cambridge University Press; 1985. 